\title{
Effect of Honey versus Icodextrin on Adhesion Reformation after Adhesiolysis: an Experimental Study in Rats
}

\author{
Aly Saber ${ }^{1}$, Mohammed H. Shekidef ${ }^{2}$, Aya Aly Saber ${ }^{1, *}$ \\ ${ }^{1}$ Port-Fouad General Hospital, Port-Fouad, Egypt \\ ${ }^{2}$ Department of Surgery, Anesthesiology and Radiology, Faculty of Veterinary Medicine, Ismailia, Suez Canal University \\ Email address: \\ shekidef77@yahoo.com (Mohammed H. Shekidef), Draya1207@gmail.com (A. A. Saber)
}

\section{To cite this article:}

Aly Saber, Mohammed H. Shekidef, Aya Aly Saber. Effect of Honey versus Icodextrin on Adhesion Reformation After Adhesiolysis: An Experimental Study in Rats. Journal of Surgery. Special Issue: Abdominal Surgery: Toward the Best. Vol. 4, No. 1-1, 2015, pp. 5-10. doi: $10.11648 /$ j.js.s.2016040101.12

\begin{abstract}
Introduction: Although the process of de novo adhesion formation after operation has been fairly well established, adhesion reformation in a previously affected zone is still poorly understood. Honey was proved effective as an anti-adhesive agent in experimental animals. The aim of the present experimental study is to investigate the effect of HONEY on adhesion reformation prevention when compared with ICODEXTRIN in rats. Materials \& Methods: 75 healthy male Sprague-Dawley rats having average weight250-300 g were divided into three groups for study: [25 rats for each], Honey, Icodextrin and control groups. Laparotomy was done carefully for not to disturb any adhesion could be attached to the previous laparotomy incision. Any adhesion band was dissected and divided gently and smoothly with sharp maneuver using fine surgical scissors. In case of groups $\mathrm{A}$ and $\mathrm{B}$, three $\mathrm{ml}$ of Honey and Icodextrin were instillated, using sterile syringes; into the abdominal cavity before completing laparotomy wound closure to prevent escape of the material outside the peritoneal cavity. Results: Total adhesion score among the three groups showed statistically significant difference using the ANOVA test but when comparing group A and $\mathrm{B}$, the difference is considered to be not statistically significant. Conclusion: Both icodextrin and honey has beneficial effect on reduction of the extent and severity of intraperitoneal adhesion reformation in our rat model for colonic anastomoses. Honey surpasses icodextrin regarding the total adhesion score and the score per animal.
\end{abstract}

Keywords: Adhesion Reformation, Honey, Icodextrin, Rats

\section{Introduction}

Intra-abdominal adhesion formation and reformation after surgery are still unavoidable events in spite of modern surgical techniques [1]. Operative trauma and surgical manipulation as well as ischaemia of the traumatized tissues induce peritoneal mesothelial damage which is considered the trigger of adhesion formation [1,2]. Although the process of de novo adhesion formation after operation has been fairly well established, adhesion reformation in a previously affected zone is still poorly understood [3 ].

After laparotomy, postoperative adhesion formation is reported to occur nearly in $100 \%$ of patients and after laparoscopic surgery, the adhesion reformation rate can be as high as 97\% [4]. For prevention of formation and reformation of post-operative intra-abdominal adhesions a variety of surgical techniques and adjuvants have been proposed. Anti-adhesive agents can be classified as pharmacological agents and intra-peritoneal barriers $[5,6]$.

Icodextrin is a non-viscous, iso-osmotic, clear solution proven safe and effective as an anti-adhesion device when used during surgery and as post-operative instillate providing a fluid reservoir in the peritoneal cavity with a prolonged residence time of up to 4 days. It acts to temporarily separate peritoneal surfaces through the process of hydroflotation, thereby minimizing tissue apposition during the critical period of fibrin formation and mesothelial regeneration following surgery, and thus providing a barrier to adhesion formation[7] and Honey was proved effective as an anti-adhesion and antibacterial agent in experimental animals $[1,8]$.

The aim of the present experimental study is to investigate the effect of HONEY on adhesion reformation prevention when compared with ICODEXTRIN in rats. 


\section{Materials \&Methods}

\subsection{Materials}

\subsubsection{Animals}

A total of 75 healthy male Sprague-Dawley rats having average weight $250-300 \mathrm{~g}$ were divided into three groups for study: [25 rats for each],Honey, Icodextrin and control groups. Rats were obtained from the documented animal house of the faculty of veterinary medicine, Suez-Canal University, Egypt. Rats were housed and fed a standard laboratory diet and water ad libitum up to $2 \mathrm{pm}$. Animals were fasted, except for water, for $12 \mathrm{~h}$ before the surgical intervention. Neither mechanical bowel preparation nor intraoperative bowel irrigation were performed. The local ethics committee for the use of laboratory animals approved all experimental procedures. Appropriate animal care and use were performed according to implementation and compliance with the Animal Welfare Act.

\subsubsection{Honey}

Honey is $18-20 \%$ water and is comprised of glucose, fructose, vitamins A, B-complex, C, D, E, K, and b-carotene, as well as minerals, antioxidants, aminoacids, and enzymes. Honey contains phenolic compounds and the enzyme glucoseoxidase, which becomes active when honey is diluted and produces hydrogenperoxide. Honey was used purified by the use of a special filter allowing separation of insect particles, spores and debris.

\subsubsection{Icodextrin}

Icodextrin is a nonviscous, iso-osmotic, clear solution having the property of a biodegradable $\alpha-1,4$-linked starch-derived glucose polymer (molecular weight $\sim 16,500$ Daltons), at a concentration of $4 \%$, in a buffered electrolyte solution (sodium $133 \mathrm{mmol} / \mathrm{L}$; chloride $96 \mathrm{mmol} / \mathrm{L}$; calcium $1.75 \mathrm{mmol} / \mathrm{L}$; magnesium $0.25 \mathrm{mmol} / \mathrm{L}$; lactate $40 \mathrm{mmol} / \mathrm{L}$, the buffer) [7].

\subsection{Methods}

\subsubsection{Anaesthesia}

General anaesthesia was induced with intramuscular Ketamine $(50 \mathrm{mg} / \mathrm{kg})$ and Xylazine $(5 \mathrm{mg} / \mathrm{kg})$. The researchers, under strict antiseptic condition, performed all surgical procedures.

\subsubsection{First Operation}

A midline laparotomy incision was done dividing skin, subcutaneous tissues and separating both recti \{Figure 1 \}. Division of the colon at the level of peritoneal reflection was performed. End-to-end single layer extramucosal anastomoses were created with eight interrupted $6 / 0$ prolene to restore the gut continuity \{Figure $2 \mathrm{a}, \mathrm{b}$ \}. Haemostasis was secured and any residual blood even so minute was removed completely and gently. No drain was left and the abdominal wound was closed in two layers with continuous $3 / 0$ silk sutures \{Figure 2 c\}.

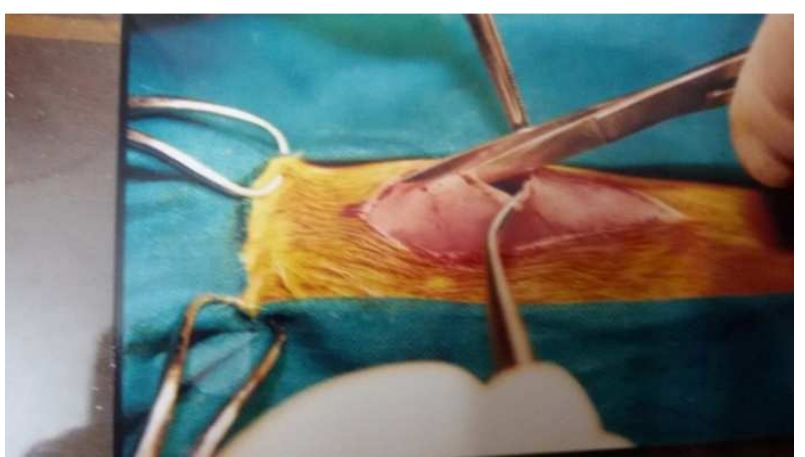

Figure 1. An operative photograph showed a midline laparotomy incision dividing skin, subcutaneous tissues and separating both recti to enter the peritoneal cavity.
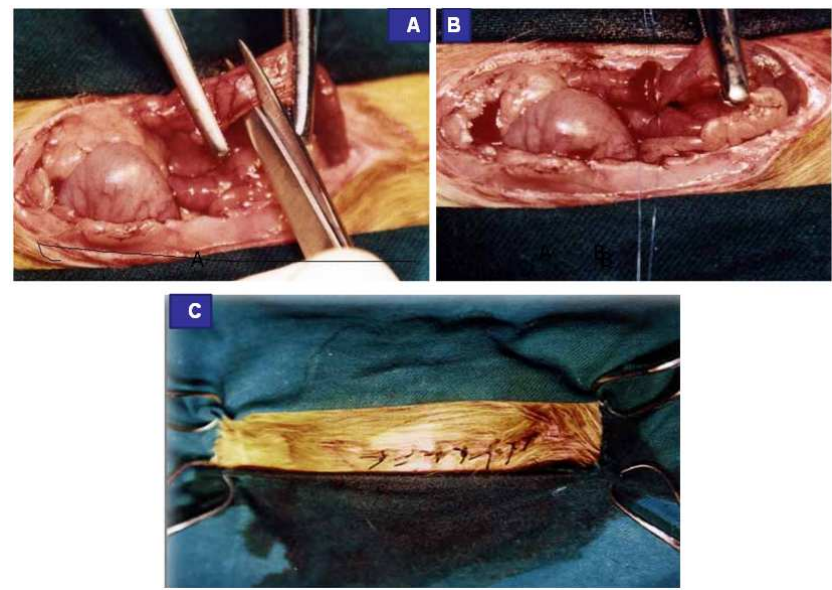

Figure 2. An operative photograph showed division of the colon at the level of peritoneal reflection [2a]. End-to-end single layer extramucosal anastomoses were created with eight interrupted $6 / 0$ prolene to restore the gut continuity [2b]. The abdominal woundwas closed in two layers with continuous 3/0 silk sutures [2c].

\subsubsection{First Post-Operative Period}

All rats were observed in the post-operative period and after the scheduled two-week's post-operative period [1], all survived rats were subjected to the second operation.
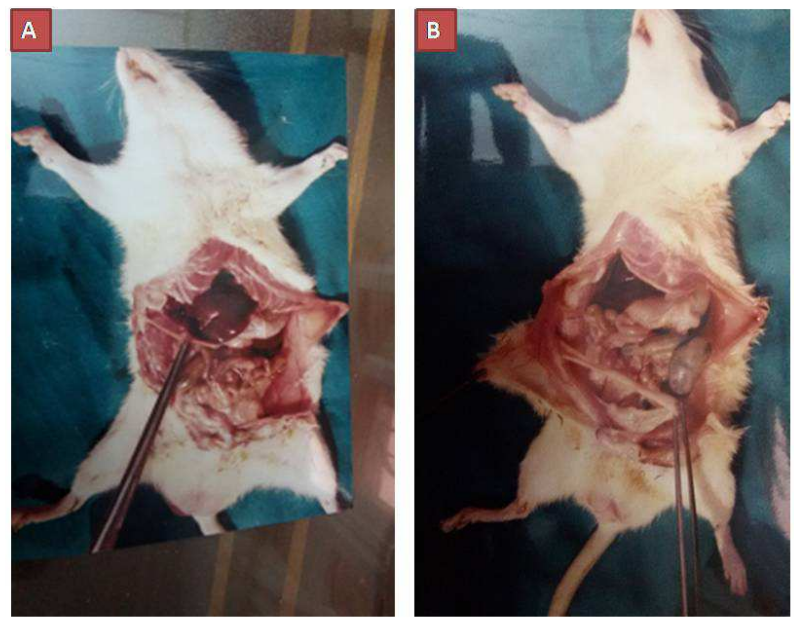

Figure 3. An operative photograph showed the second laparotomy made carefully for not to disturb any adhesion could be attached to the previous laparotomy incision. 


\subsubsection{Second Operation}

Laparotomy was done carefully for not to disturb any adhesion could be attached to the previous laparotomy incision. Any adhesion band was dissected and divided gently and smoothly with sharp maneuver using fine surgical scissors \{Figure 3 \}. Securing hemostasis was achieved and the tested materials were instilled within the peritoneal cavity.

\subsubsection{Instillation of Tested Materials}

In case of groups A and B, three $\mathrm{ml}$ of Honey and Icodextrin were instillated, using sterile syringes; into the abdominal cavity before completing laparotomy wound closure to prevent escape of the material outside the peritoneal cavity. In group $\mathrm{C}$, nothing was instillated at the end of operation $\{$ Figure 4$\}$.

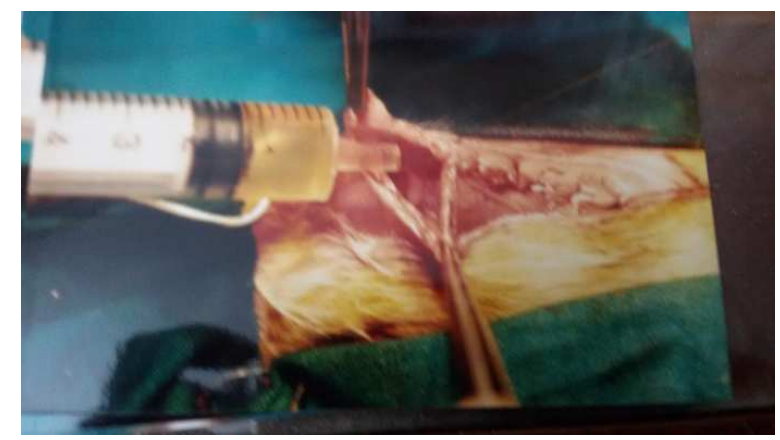

Figure 4. An operative photograph showed instillation of tested materials into the peritoneal cavity only for group $A$ and $B$.

\subsubsection{Second Post-Operative Period}

All rats were observed during the second postoperative period and data was collected day by day and saved as soft-ware files for later evaluation. After the scheduled twoweek's post-operative period [1], all survived rats were reopened for second-look laparotomy to detect the characters of adhesion reformation after sharp adhesiolysis.

\subsubsection{Study of Adhesion Reformation}

Subsequently, adhesion reformation was scored blindly by two independent observers unaware of the groups. Two parallel systems were used to evaluate both the degree of severity and the extent of adhesion. As regard to the degree of severity of the formed adhesions in all groups, the 4-point scale system was used: grade 0: no adhesions, grade 1: thin, few and filmy, grade 2: thick and avascular and grade 3: thick, vascular and extensive. As regard to the extent of adhesion formation in all groups the 4 -point scale system was used: $0=$ none, $1=$ localized, $2=$ moderate and $3=$ extensive.

\subsubsection{Calculation of the Total Adhesion Scores}

The total adhesion score for each animal was the sum of these two scores (extent and severity), with a maximum total score of 6.

\section{Statistical analysis:}

The statistical tests were run on a compatible personal computer using the Statistical Package for Social Scientists ( SPSS ) for windows 15. The mean values of the groups were compared by one-way analysis of variance (ANOVA) as well as the least significant difference (Tukey's Honestly Significant Difference) as a post hoc test. $\mathrm{P}<0.05$ was considered significant.

\section{Results}

The overall mortality rate in the present study was $9.3 \%$ [ $7 /$ 75 rats]. In honey group, the mortality was $4 \%$ [1/25] while in both icodextrin and control groups, the mortality was $12 \%[3 /$ 25]. This distribution is insignificant $\{P \geq 0.05\}$.

Adhesion reformation study:

A-Extent of adhesion:

Adhesion extent was given a score value as the 4-point grading system [ values 0-3 ] as advocated in our previous study [1]; no adhesion [value $=0$ ], localized adhesion [ value $=1$ ], moderate adhesion [value $=2$ ] and extensive adhesion [ value $=3]$.

1-Localized adhesion was detected in the form of perianastomotic adhesion formed of small gut loops or omentum in 12 rats of honey group, 11 rats of icodextrin group and in 4 rats of control group \{Figure 5a\}.

2-Moderate adhesion was observed in the form of perianastomotic adhesion formed of small intestinal loops or omentum plus a single band extending between the abdominal surface of the wound and the omentum or adherence of two loops of gut in 10 rats of honey group, 8 rats of icodextrin group and 7 rats of control group $\{$ Figure $5 \mathrm{~b}\}$.

3-Extensive adhesion was detected between the small intestine, omentum and the anastomotic site in 2 rats of honey group, 3 rats of icodextrin group and 11 rats of control group $\{$ Figure $5 \mathrm{c}$ \}. This distribution is statistically significant; $\mathrm{P}$ value equals 0.0004and Chi squared equals 18.211. \{table 1 and graph 1 \}
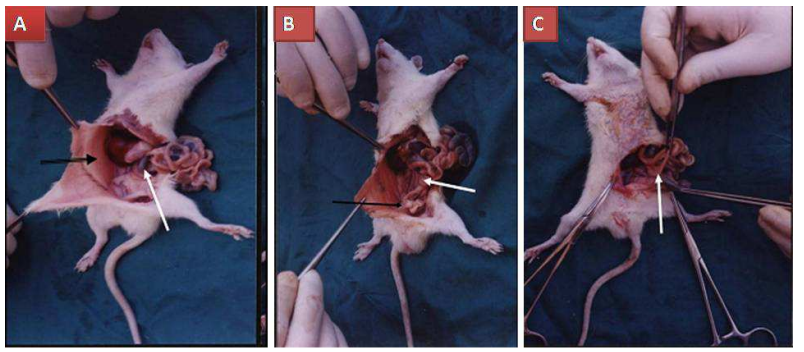

Figure 5. An operative photograph showed the extent of adhesion. Localized adhesion was detected in the form of perianastomotic adhesion formed of small gut loops [5A],moderate adhesion in the perianastomotic area formed of small intestinal loops and omentum [5B] and extensive adhesion between the small intestine, omentum and the anastomotic site [5C].

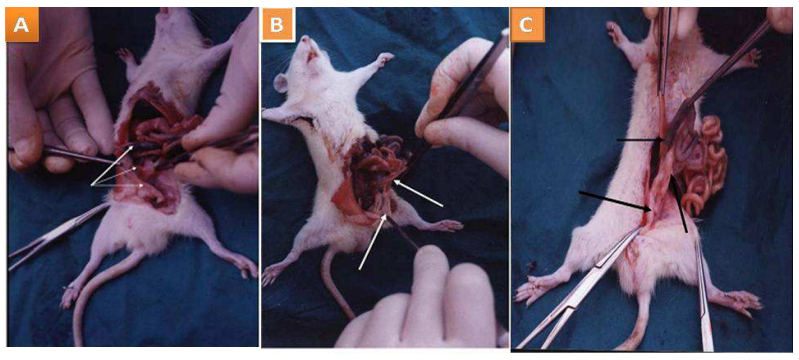

Figure 6. An operative photograph showedthe severity of adhesion. 
Table 1. Showed the distribution of extent of adhesion in the three groups of the study.

\begin{tabular}{lllll}
\hline Group & Localized & Moderate & Extensive & Total \\
\hline A & 12 & 10 & 2 & 24 \\
B & 11 & 8 & 3 & 22 \\
C & 4 & 7 & 11 & 22 \\
\hline
\end{tabular}

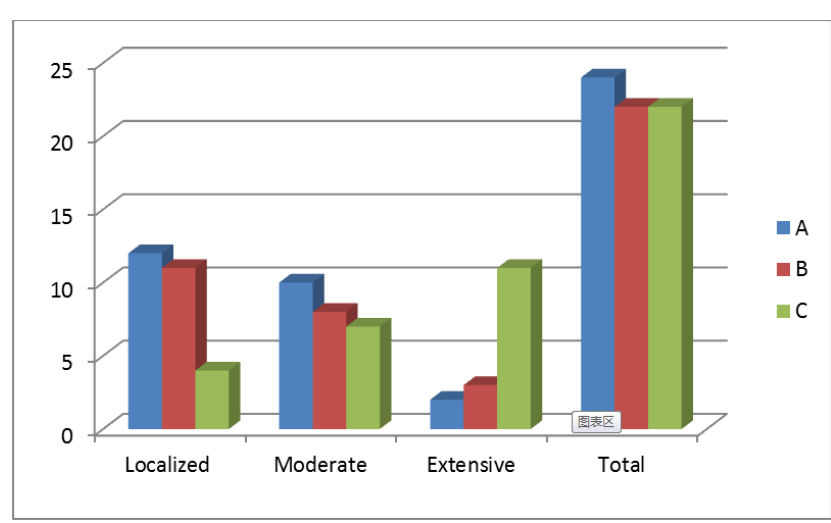

Graph 1. Showed the distribution of extent of adhesion in the three groups of the study.

\section{B-Severity of adhesion:}

Adhesion severity was given a score value as the four grading system of severity [values $0-3$ ]: no adhesion [value $=0$ ], thin filmy adhesion [value $=1$ ], thick avascular adhesion [value $=2$ ] and thick vascular adhesion [value $=3$ ].This distribution is statistically significant; $P$ value is $\leq 0.0001$ and Chi squared equals 39.086. \{table 2 and graph 2$\}$

Table 2. Showed the distribution of severity of adhesion in the three groups of the study.

\begin{tabular}{lllll}
\hline Group & $\begin{array}{l}\text { Thin } \\
\text { filmy }\end{array}$ & $\begin{array}{l}\text { Thick } \\
\text { avascular }\end{array}$ & $\begin{array}{l}\text { Thick } \\
\text { vascular }\end{array}$ & Total \\
\hline A & 18 & 4 & 2 & 24 \\
B & 12 & 8 & 2 & 22 \\
C & 3 & 5 & 14 & 22 \\
\hline
\end{tabular}

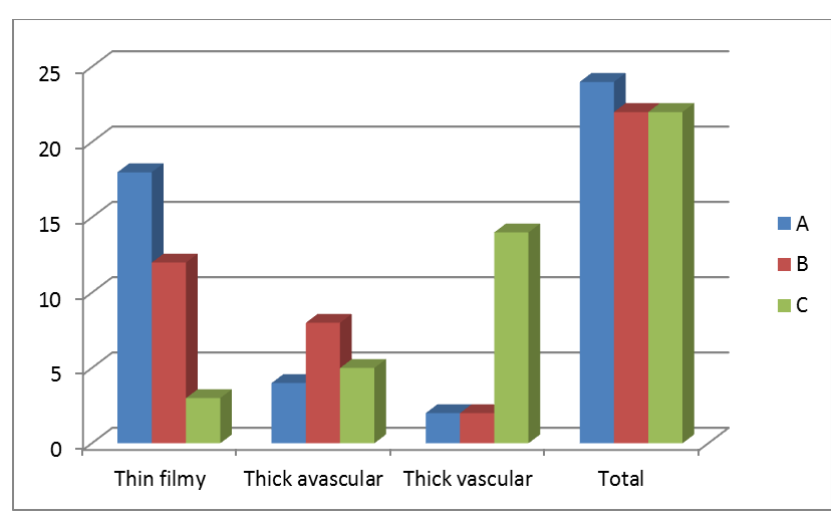

Graph 2. Showed the distribution of severity of adhesion in the three groups of the study.

\section{C-Total adhesion score: $\{$ table 3$\}$}

Adhesions were scored according to an extent scale and a severity scale (range, $0-3$ ). The total adhesion score for each animal was the sum of these two scores (extent and severity), with a maximum total score of 6 [1].
The total adhesion scoring for the honey-treated animals was 70 and the average score per rat was 2.9 and the total adhesion scoring for the icodextrin -treated animals was 79 and the average score per rat was 3.14 while in case of the control untreated animals the total adhesion scoring was 106 and the average score per rat was 4.83 .

Total adhesion score among the three studied groups showed statistically significant difference using the ANOVA test between the three groups. $\mathrm{P}$-value $<0.001$; but when comparing group $\mathrm{A}$ and $\mathrm{B}$, the difference is considered to be not statistically significant [P value equals 0.6222]. \{table 3 and graph 3 .

Table 3. Shows the total adhesion scoring in the three groups as well as the score per rat.

\begin{tabular}{lll}
\hline Group & Totalscore & Scoreperrat \\
\hline A & 70 & 2.9 \\
B & 79 & 3.14 \\
C & 106 & 4.83 \\
\hline
\end{tabular}

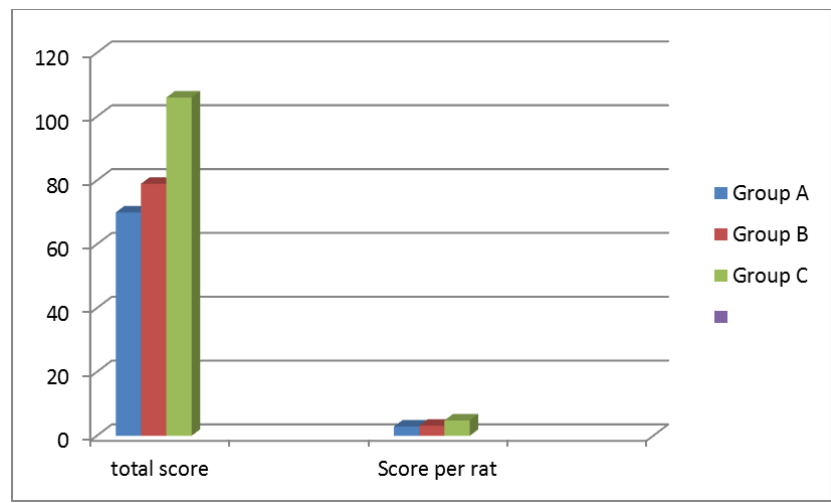

Graph 3. Shows the total adhesion scoring in the three groups as well as the score per rat.

\section{Discussion}

The formation of postoperative peritoneal adhesions after abdominal surgery remains a major surgical problem causing complications like chronic pain, infertility and intestinal obstruction $[9,10]$. Intra-abdominal application of various substances including honey and 4\% icodextrin solution were used in experimental and clinical aspects in order to reduce peritoneal adhesions $[1,7,9,10]$. Adhesion formation and reformation after adhesiolysis are usually assessed by both extent and severity $[1,11]$. Open adhesiolysis for the denovo adhesion formation may be more beneficial in minimizing adhesion reformation in the management of adhesion-related complications [12]. Laparoscopic surgery for adhesiolysis improves clinical outcomes and can be performed safely in selected cases with similar rates of bowel injury and reoperation to open surgery. Large scale randomized controlled trials are needed to validate the findings of this pooled analysis of non-randomized data [13].

Several studies showed a significant reduction of adhesion formation after abdominal surgery due to the application of icodextrin $[7,9,10,14]$ while others do not $[15,16]$. On the 
other hand, honey was used in experimental animals to reduce the de novo intraperitoneal adhesion and was proved effective in reducing both the extent and severity of these adhesions [1, 17-19]. The present study reported data that came in agreement with those published in the previous studies. In our data, honey and icodextrin reduced both the extent and severity of adhesion reformation after sharp open adhesiolysis compared with the control rats. However, honey was observed much more effective than icodextrin in these effects as the total adhesion score and the score per each animal were lower in case of honey-treated rats.

The side effect of icodextrin has been largely concerned with skin rashes and generalized exfoliative dermatitis are unknown [ 20].Urinary retention and vulvar edema are well-documented side effects following laparoscopic gynaecological surgery associated with the use of $4 \%$ icodextrin $[21,22]$. Hemodynamic effects include hypotension and metabolic effects resulting in misleading glucose readings on non-specific glucometers [23].

On the other hand, the safety of honey was documented by many researchers in clinical and experimental levels. Honey was used extensively as a topical agent for wound dressing in general [24], in diabetic foot gangrene $[25,26]$ and in pediatric and neonatal groups [27]. When used on cesarean section incision, topical honey is suggested as a natural product with rare side effects in order to reduce the complications of cesarean wounds [28].The acidic $\mathrm{pH}$ of honey makes it a potential treatment for lowering wound $\mathrm{pH}$, but the duration of effect is unknown. Lowering wound $\mathrm{pH}$ can potentially reduce protease activity, increase fibroblast activity and increase oxygen release consequently aiding wound healing [29,30].

\section{Conclusion}

Both icodextrin and honey has beneficial effect on reduction of the extent and severity of intraperitoneal adhesion reformation in our rat model for colonic anastomoses. Honey surpasses icodextrin regarding the total adhesion score and the score per animal.

\section{References}

[1] Aly Saber. Effect of honey versus intergel in intraperitoneal adhesion prevention and colonic anastomotic healing: A randomized controlled study in rats. I J S, 8 (2010) 121-127

[2] Roman H, Canis M, Kamble M, et al. Efficacy of three adhesion-preventing agents in reducing severe peritoneal trauma induced by bipolar coagulation in a laparoscopic rat model. FertilSteril. (2005).83 Suppl 1:1113-8.

[3] Gómez-Gil V, García-Honduvilla N, Pascual G, Rodríguez M, Buján J, Bellón JM. Peritoneal adhesion formation and reformation tracked by sequential laparoscopy: Optimizing the time point for adhesiolysis. Surgery. $2010 ; 147(3): 378-91$

[4] Muzii L. Survey among Members of the Roman Group of Gynecologic Endoscopy on the Use of Agents for Postoperative Adhesion Prevention. J Am Assoc Gynecol Laparosc. 2004 ;11(2):248-51.
[5] Pados G, Makedos A and Tarlatzis B.(2013); Adhesion Prevention Strategies in Laparoscopic Surgery. In: Endoscopy. SomchaiAmornyotin (ed). InTech. Page: 49-72

[6] Sutton, C. Adhesions and their prevention. Obstet. Gynaecol. 2005; 7: 168-176.

[7] Trew G, Pistofidis G, Pados G, Lower A, Mettler L, Wallwiener D, Korell M, Pouly JL, Coccia ME, Audebert A, Nappi C, Schmidt E, McVeigh E, LandiS,Degueldre M, Konincxk P, Rimbach S, Chapron C, Dallay D, Röemer T, McConnachie A, Ford I, Crowe A, Knight A, Dizerega G, Dewilde R.Gynaecological endoscopic evaluation of $4 \%$ icodextrin solution: a European, multicentre, double-blind, randomized study of the efficacy and safety in the reduction of de novo adhesions after laparoscopic gynaecological surgery. Hum Reprod.2011 ;26(8):2015-27.

[8] Saber A, Shekidef MH, El-Daharawy MH. Fecal Peritonitis in Rats.J. Adv. Vet. Res. 2011; 1(1): 8-12.

[9] Klink CD1, Schickhaus P, Binnebösel M, Jockenhoevel S, Rosch R, Tolba R, Neumann UP, Klinge U.Influence of 4\% icodextrin solution on peritoneal tissue response and adhesion formation. BMC Surg. 2013 Sep 10;13:34. doi: 10.1186/1471-2482-13-34.

[10] Shi Z, Ma L, Yang Y, Wang H, Schreiber A, Li X, et al.: Adhesion formation after previous caesarean section-a meta-analysis and systematic review. BJOG 2011, 118:410-422.

[11] Luciano DE, Roy G, Luciano AA. Adhesion Reformation After Laparoscopic Adhesiolysis: Where, What Type, and in Whom They Are Most Likely to Recur. J Minim Invasive Gynecol.2008;15(1):44-8.

[12] Prushik SG, Stucchi AF, Matteotti R, Aarons CB, Reed KL, Gower AC, Becker JM. Open adhesiolysis is more effective in reducing adhesion reformation than laparoscopic adhesiolysis in an experimental model. Br J Surg. 2010 Mar;97(3):420-7.

[13] Wiggins T, Markar SR, Harris A. Laparoscopic adhesiolysis for acute small bowel obstruction: systematic review and pooled analysis. SurgEndosc. 2015 Apr 4. [Epub ahead of print]

[14] Schnuriger B, Barmparas G, Branco BC, Lustenberger T, Inaba $\mathrm{K}$, Demetriades D:Prevention of postoperative peritoneal adhesions: a review of the literature. Am J Surg 2011, 201:111-121.

[15] Wallwiener M, Brucker S, Hierlemann H, Brochhausen C, Solomayer E, Wallwiener C:Innovative barriers for peritoneal adhesion prevention: liquid or solid? A rat uterine horn model. FertilSteril 2006, 86:1266-1276.

[16] Muller SA, Weis C, Odermatt EK, Knaebel HP, Wente MN: A hydrogel for adhesion prevention: characterization and efficacy study in a rabbit uterus model. Eur J ObstetGynecolReprodBiol 2011, 158:67-71.

[17] Celepl S, Kismet K, Kaptanoğlu B, Erel S, Ozer S, Celeplı P, Kaygusuz G, Devrım E, Gencay O, Sorkun K, Durak I, Akkuş MA. The effect of oral honey and pollen on postoperative intraabdominal adhesions. Turk J Gastroenterol.2011;22(1):65-72.

[18] Yuzbasioglu MF, Kurutas EB, Bulbuloglu E, Goksu M, Atli Y, Bakan V, Kale IT. Administration of honey to prevent peritoneal adhesions in a rat peritonitis model.Int J Surg. 2009; 7(1):54-7 
[19] Emre A, Akin M, Isikgonul I, Yuksel O, Anadol AZ, Cifter C. Comparison of intraperitoneal honey and sodium hyaluronate-carboxymethylcellulose (Seprafilm) for the prevention of postoperative intra-abdominal adhesions. Clinics (Sao Paulo). 2009; 64(4):363-8.

[20] Cnossen TT, Konings CJ, van der Sande FM, Leunissen KM, Kooman JP. Clinical effects of icodextrin in peritoneal dialysis. NDT Plus. 2008 Oct;1(Suppl 4):iv18-iv22. doi: 10.1093/ndtplus/sfn119.

[21] Reed B, Robinson R. Postoperative Urinary Retention With Gross Vulvar Edema After Use of 4\% Icodextrin. Mil Med. $2015 \mathrm{Jul} ; 180(7)$ :e858-60.

[22] Nesbitt-Hawes EM, Zhang CS, Won HR, Law K, Abbott JA. Urinary retention following laparoscopic gynaecological surgery with or without $4 \%$ icodextrin anti-adhesionsolution. Aust N Z J ObstetGynaecol. 2013 Jun;53(3):305-9

[23] Silver SA, Harel Z, Perl J. Practical considerations when prescribing icodextrin: a narrative review. Am J Nephrol. 2014;39(6):515-27.

[24] Jull AB, Cullum N, Dumville JC, Westby MJ, Deshpande S, Walker N. Honey as a topical treatment for wounds. Cochrane Database Syst Rev. 2015 Mar 6; 3:CD005083. Epub 2015 Mar 6.
[25] Mohamed H, Salma MA, A Lenjawi B, Abdi S, Gouda Z, Barakat N, Elmahdi H, Abraham S, Hamza AH, Al Khozaei D, A Majid S, A MajidH,Abdini J, Al Jaber M, A Masseh F, Al Ali AA. The efficacy and safety of natural honey on the healing of foot ulcers: a case series. Wounds. 2015 Apr;27(4):103-14.

[26] Kosternoy A, Bayumi EK. Use of Honey in Management of Diabetic Foot Infection: Patient's Satisfaction and Outcome. Journal of Surgery 2015; 3(2-1): 42-47

[27] Amaya R. Safety and efficacy of active Leptospermum honey in neonatal and paediatric wound debridement.J Wound Care. 2015 Mar;24(3):95; 97-103.

[28] Nikpour M, Shirvani MA, Azadbakht M, Zanjani R, Mousavi E. The effect of honey gel on abdominal wound healing in cesarean section: a triple blind randomized clinical trial. Oman Med J. 2014 Jul;29(4):255-9.

[29] Gethin GT, Cowman S, Conroy RM. The impact ofManuka honey dressings on the surface $\mathrm{pH}$ of chronic wounds. Int Wound J.2008;5(2):185-94.

[30] Zhou J, Pi H, Zheng Y. Characteristics of abdominal cavity drainage fluid in Chinese patients without postoperative complications aftersurgery for gastrointestinal or retroperitoneal tumors. ClinInterv Aging. 2015 Jan 28;10:367-70. 